\title{
OPTİK GÖRÜNTÜLERDEN KONUM BİLGİSİ ELDE ETMEDE KULLANILAN ALGILAYICI YÖNELTME YÖNTEMLERİ
}

\author{
Hüseyin Topan \\ Doç. Dr., Zonguldak Bülent Ecevit Üniversitesi, Mühendislik Fakültesi, Geomatik Mühendisliği Bölümü, 67100, Zonguldak, topan@ beun.edu.tr
}

\begin{abstract}
ÖZET
Optik görüntüler, fotogrametri, uzaktan algılama, bilgisayarla görme ve derin öğrenme çalışmalarında en sık kullanılan veri türüdür. Görüntülerden konuma bağll bilgi elde edilmesi, temelde görüntü koordinat sistemi ile nesne koordinat sistemi arasındaki dönüşümün sağlanması ile mümkündür. Genel olarak "algılayıcı yöneltmesi”" adı verilen bu dönüşüm işlemi, algılayıcı ve taşıyıcı geometrisini kullanan ve kullanmayan yöntemler ile koordinatlandırılmış görüntü, mozaik görüntü, ortogörüntü ve Sayısal Yükseklik Modeli gibi konum bilgisi içeren farklı türde ürünlerin üretilmesinde kullanılmaktadır. Bu ürünlerin doğrudan konuma bağll uygulamalarda kullanılmasının yanında çevre, ormancılık, tarım, peyzaj, şehir ve bölge planlama, arkeoloji, savunma vb. farklı uygulamalarda da birer altlı olarak kullanılması söz konusudur. Dolayısıyla ürünlerin elde edilmesinde kullanılan yöntemlerin özellikleri hem ürünün kalitesini hem de ürünün kullanıldığı uygulamanın bașarısını etkileyecektir.

Ülkemizde gerçekleştirilen uygulamalara bakıldı̆̆ında, yukarıda bahsedilen ürünlerin üretiminde genellikle kullanıcı müdahalesinin sınırlı olduğu ticari yazılımların kullanıldı̆̆ görülmektedir. Giderek yaygınlaşan açık erişimli yazılımların kullanımı artsa da kullanıcılar özellikle algılayıcı yöneltmesi yöntemine müdahale etmemektedir. Bu eksiklik ancak algılayıcı yöneltme yöntemlerinin aralarındaki farkların, kullanılabileceği algılayıcı ve ürünlerin iyi bilinmesi; ayrıca dengeleme işlemlerinin ve sonuç doğruluk araştırmasının nasıl yapılacağının kavranması ile aşılabilir.

Bu bildiride, insansız hava araçlarından yüksek çözünürlüklü uydu görüntülerine kadar geniş bir yelpazede kullanımına gereksinim duyulan algılayıcı yöneltme yöntemleri, aralarındaki farklar, dengeleme ve sonuç doğruluk işlemleri hakkında bilgiler verilecektir.
\end{abstract}

Anahtar Sözcükler: fotogrametri, uzaktan algılama, algılayıcı yöneltmesi, algılayıcıya bağımlı yöneltme, algılayıcıdan bağımsız yöneltme

\section{ABSTRACT \\ SENSOR ORIENTATION MODELS USED FOR GENERATION OF GEOSPATIAL INFORMATION FROM OPTICAL IMAGES}

Optical images are the most common input data used in photogrammetry, remote sensing, computer vision and deep learning applications. Generation of geospatial information from images is based on the transformation between image and object coordinate systems. This transformation is generally called "sensor orientation", and is used for generation of various kinds of geospatial products such as georeferenced image, mosaic image, orthoimage and Digital Elevation Model. Such kinds of products are not used only in geospatial applications but also in environmental, forestry, agricultural, landscape architecture, urban and regional planning, archaeology, defence etc. The characteristics of methods affects both the quality of products and the success of application where the product is used.

When the nation-wide applications are reviewed, it can be said that the commercial software which the user cannot fully control all steps is used in the generation of products aforementioned. Although open access software becomes more common than in the past, users refrain changing the options of sensor orientation. This challenge could be overcome with the help of knowledge of difference among the sensor orientation models, suitable imaging sensors and products which the model can be used in. Besides, how the adjustment process and final accuracy assessment will be held are the other vital issues.

This paper presents wide-range of information about sensor orientation models which is widely used for unmanned aerial vehicles and high resolution satellite images.

Keywords: photogrammetry, remote sensing, sensor orientation, sensor dependent orientation, sensor independent orientation

\section{GíRiş}

Optik görüntüler, fotogrametri, uzaktan algılama, bilgisayarla görme ve derin öğrenme çalışmalarında yaygın olarak kullanılan bir veri türüdür. Tarihî süreçte “analog fotoğraf” olarak elde edilen görüntüler, günümüzde yerini tamamen "elektro-optik" görüntüye bırakmıştır. Optik bir görüntü, 3B (3 boyutlu) nesne uzayının 2B (2 boyutlu) görüntü uzayına merkezî bir izdüşümüdür. Bu izdüşüm, uzaktan algılamada kullanılan algılayıcıların dar görüş alanı nedeniyle paralel izdüşüm hâlini alır (Okamoto, 1992). Ham bir görüntü ile sadece satır ve sütun değerlerinden oluşan görüntü koordinatları elde edilir. Görüntü kullanılarak nesne koordinatlarının elde edilebilmesi için ise görüntü ve nesne koordinat sistemleri arasındaki koordinat dönüşümünün gerçekleştirilmesi gerekir. Genel olarak algılayıcı yöneltmesi olarak adlandırılan bu işlem algılayıcıya bağımlı ve algılayıcıdan bağımsız olmak üzere iki çeşit yöntem ile gerçekleştirilir. Yöntemin özelliklerine göre tek (mono) veya bindirmeli (stereo) görüntülerden 2/3B nesne 
koordinatlarını elde etmek mümkündür. Böylece koordinatlandırılmış görüntü, mozaik görüntü, ortogörüntü ve SYM (Sayısal Yükseklik Modeli) gibi konum bilgisi içeren farklı türde ürünlerin üretilmesi mümkündür.

Bu bildiride, insansız hava araçlarından yüksek çözünürlüklü uydu görüntülerine kadar geniş bir yelpazede kullanılan algılayıcı yöneltme modelleri, aralarındaki farklar, dengeleme ve sonuç doğruluk işlemleri, 2/3B koordinat bilgisi elde etmede nasıl kullanıldıkları hakkında bilgiler verilecektir.

\section{ALGILAYICI YÖNELTME YÖNTEMLERİ}

Algılayıcı yöneltme yöntemleri temelde algılayıcıya bağımlı ve algılayıcıdan bağımsız olmak üzere ikiye ayrılır. Bu yöntemlerin temel özellikleri şöyle sıralanabilir:

a) Algılayıcıya bağımlı yöntemler, algılayıcının ve taşıııcının geometrik özelliklerini dikkate alırlar.

b) Kuramsal olarak algılayıcıya bağımlı bir yöntem, fotogrametride kullanılan eşdoğrusallık bağıntıları dışında YKN'ye (Yer Kontrol Noktası) ihtiyaç duymaz. Ancak yüksek konum doğruluğu için algılayıcı ve taşıyıcı sisteme ait parametrelerin (elemanların) düzeltilmesi gerekir. Bu nedenle YKN, çizgisel özellikteki nesneler veya SYM gibi ek verilerin kullanımı kaçınılmazdır.

c) Algılayıcıdan bağımsız yöntemler algılayıcının ve taşıııcı sistemin geometrik özelliklerini dikkate almazlar.

d) Algılayıcıdan bağımsız yöntemlerin katsayıları YKN veya çizgisel özellikteki nesneler yardımıyla belirlenir.

e) Dengeleme ile hem görüntü koordinatlarına hem de yöneltme ögelerine/katsayılarına düzeltme getirilebilir. Bunun için faklı dengeleme yöntemleri kullanılmaktadır.

f) Dönüşüm işleminde kötü konum ve kötü koşul sorunu ile karşılaşmak olasıdır. Bu sorunun çözümü için düzenlileştirme, normalleştirme, farklı matris tersi alma veya indirgeme yöntemleri kullanılmaktadır.

Görüntünün geometrik özellikleri, algılayıcı ve taşıyıcı sistemin geometrik özelliklerine bağlı olduğundan, görüntüleme geometrisi konusunu da özetle ele almak açısından öncelikle algılayıcıya bağımlı yöntemler tanitilacaktir.

\subsection{Algılayıcıya Bağımlı Yöntemler}

Algılayıcıya bağımlı yöntemler, görüntü ve nesne koordinat sistemi arasındaki dönüşümü gerçekleştirirken algılayıcı ve taşıyıcı sistemin geometrik özelliklerini dikkate almaktadırlar. Bu yöntemler, fotogrametri ve uzaktan algılama için iki farklı bölümde ele alınacaktır. Aralarındaki fark, uzaktan algılamada kullanılan taşıyıcı sistemin (yapay uydu) bir yörüngede hareket etmesinden kaynaklanan ek bazı koordinat sistemleri kullanmasıdır.

\subsubsection{Fotogrametride Kullanılan Yöntemler}

Öncelikle fotogrametride en yaygın bilinen eşdoğrusallık bağıntıları üzerinde durulacaktır. Bu bağıntının dayandığı geometrik ilişki Şekil 1 a'da gösterilmektedir. Görüntü merkezi bir izdüşümle elde edilir ve izdüşüm merkezi kamera optik sisteminin merkezidir $(O)$. Görüntï koordinat sistemi $(x, y)$ ile nesne koordinat sistemi $(X, Y, Z)$ arasindaki dönüşüm, $O$ merkez alınarak $O$ 'nun ve nesnenin $(P)$ görüntü ve nesne uzayındaki karşılıkları ile oluşturulan üçgenler yardımıyla (1) numaralı eşitlik ile tanımlanır.

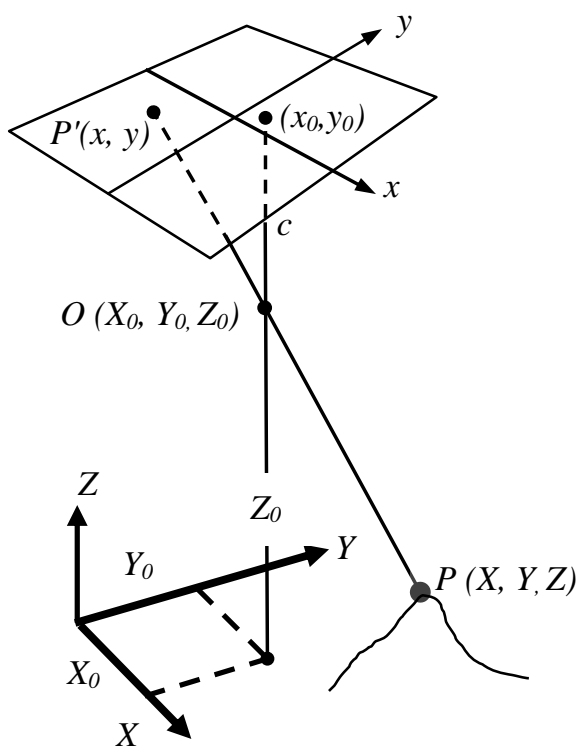

a) Eşdoğrusallık bağıntılarının elde edildiği fotogrametrik görüntü alım durumu.

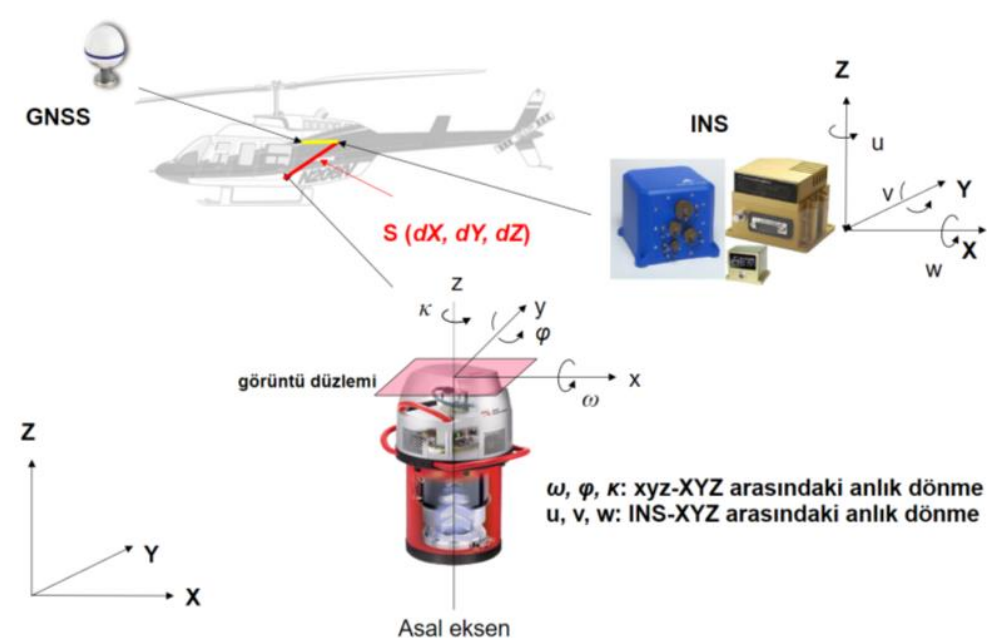

b) Fotogrametride kamera, INS/IMU ve GNSS alıcısının durumu.

Şekil 2. Algılayıcıya yarı-bağımlı yöntemler için geometrik temeller. 


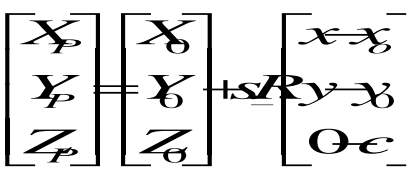

Burada $X_{P}, Y_{P}, Z_{P} P$ 'nin nesne koordinatlarını, $X_{O}, Y_{O}, Z_{O} O$ 'nun nesne koordinatlarını, $s$ ölçeği, $\underline{R}$ görüntü ve nesne koordinat sistemleri arası dönmeyi, $x, y$ görüntü koordinatlarını, $x_{o}, y_{o} O$ 'nun görüntü koordinat sistemindeki karşılığını (asal noktanın konumunu) ve $c$ odak uzaklığını temsil etmektedir. Analog fotoğraflar kullanıldığında görüntü koordinat sistemi çerçeve işaretleri kullanılarak yeri belirlenen orta noktadan başlarken sayısal görüntülerde ise bu görüntülerin matris yapısı nedeniyle görüntünün sol üst köşesinden başlayarak satır ve sütun yönünde tanımlanır. $\underline{R}$ dönme matrisi ise görüntünün koordinat sisteminin üç ekseni $(x, y, c)$ ile nesne koordinat sistemi eksenleri $(X, Y, Z)$ arasında sırasıyla $\omega, \varphi, \chi$ açılarıyla tanımlanan ve pozitif değerleri saat ibresinin tersi olarak kabul edilen açılardan hesaplanmaktadır. Bu dönme, görüntüleme sistemini taşıyan sistemin hareketinden ve rüzgâr gibi etkenlerden kaynaklanmaktadır. İç yöneltme öğeleri $\left(x_{o}, y_{o}, c\right)$ ise kamera kalibrasyon raporu ile veya kullanıcı tarafından test görüntüleri çekilerek belirlenebilir (Kraus, 1993). Kamera kalibrasyon raporları, çerçeve işaretlerinin ve asal noktanın görüntü koordinatları, mercek bozunum değerleri ve odak uzaklığı gibi değerlerin olduğu bir rapordur. Bu bağıntılarda iç yöneltme ögeleri $\left(x_{o}, y_{o}, c\right)$ kameraya özgü olarak değişse dahi diş yöneltme ögeleri YKN yardımıyla $\left(X_{0}, Y_{0}, Z_{0}, \omega, \varphi, \kappa\right)$ uzay geriden kestirme ile hesaplanarak elde edilmektedir (Örmeci, 1988).

Teknolojinin gelişmesiyle birlikte taşıyıcı sistemin dönüklüğünün INS/IMU (Inertial Navigation System/Inertial Measurement Unit) ve taşıyıcı sistemin konumu GNSS (Global Navigation Satellite Systems) alıcısı ile belirlenir (Şekil 1 b). Dolayısıyla görüntü koordinat sistemi $(x, y)$ ile nesne koordinat sistemi $(X, Y, Z)$ arasındaki dönüşüm görüntü $\leftrightarrow$ kamera $\leftrightarrow$ INS/IMU $\leftrightarrow$ GNSS $\leftrightarrow$ yer koordinat sistemleri arasındaki dönüşümün tanımlanması ile mümkündür. Doğrudan algılayıcı yöneltmesi adı verilen bu yöntemin bağıntısı şöyledir:

$$
\left[\begin{array}{c}
X \\
Y \\
Z
\end{array}\right]_{i}=\left[\begin{array}{c}
X_{0} \\
Y_{0} \\
Z_{0}
\end{array}\right]^{\text {ins }} \cdot\left[\begin{array}{c}
d X \\
d Y \\
d Z
\end{array}\right]+s \cdot \underline{R}_{\text {ins }}^{y e r} \cdot d \underline{R}_{g o ̈ r}^{i n s} \cdot\left[\begin{array}{c}
x-x_{0} \\
y-y_{0} \\
-c
\end{array}\right]
$$

Burada, kamera koordinat sistemi ile görüntü koordinat sistemi arasındaki dönüşüm iç yöneltme ile gerçekleştirilir. $d \underline{R}_{g o ̈ r}^{i n s}$, kamera ve INS/IMU arasındaki dönüklüğ̈̈, $\underline{R}_{i n s}^{y e r}$ ise INS/IMU ile yer koordinat sistemi arasındaki dönüklüğü temsil eder. Ölçek $s$ ile gösterilmektedir. $d X, d Y, d Z$ ise INS/IMU ve GNSS arasındaki mesafenin koordinat bileşenleri, $\left(X_{0}, Y_{0}, Z_{0}\right)$ ise GNSS alıcısı ile elde edilen yer koordinatlarıdır. Böylece nesne koordinatları $(X, Y, Z)$ elde edilir (Yastıklı, 2004). (1) ve (2) numaralı bağıntılar, sadece uçak veya helikopter gibi insanlı hava araçları ile yapılan fotogrametri çalışmalarında değil, günümüzde kullanımı yaygınlaşan UKHA (Uzaktan Kumandalı Hava Aracı) veya İHA (İnsansız Hava Aracı) olarak adlandırılan sistemlerle gerçekleştirilen eğik bakışlı veya yersel (yakın saha) fotogrametri çalışmalarda da kullanılabilir (Niu vd., 2006; Zhou, 2009). Aralarındaki fark, GNSS ve INS/IMU gibi sistemlerin kullanılmadığı durumlarda (1) numaralı bağıntı geçerli iken bu sistemlerin kullanıldığı durumlarda (2) numaralı bağıntının geçerli olmasıdır. Dengeleme işleminde dış yöneltme elemanlarına düzeltme getirilebileceği gibi iç yöneltme elemanları da hatalı kabul edilerek kendiliğinden (oto) kalibrasyon yaklaşımı ile düzeltilebilir.

\subsubsection{Uzaktan Algılamada Kullanılan Yöntemler}

Fotogrametridekine ek olarak uzaktan algılamada kullanılan algılayıcıya bağımlı yöneltme yöntemlerinde uydu yörüngesi ile ilgili koordinat sistemlerinin de dikkate alınması gerekir. Günümüzde çoğu optik görüntünün doğrusal dizin sistemler ile elde edildikleri göz önüne alındığında görüntü ile nesne koordinat sistemleri arasındaki dönüşüm görüntü $\leftrightarrow$ doğrusal dizin (satır) $\leftrightarrow$ kamera $\leftrightarrow$ uydu $\leftrightarrow$ yörünge $\leftrightarrow$ inersiyal $\leftrightarrow$ yer koordinat sistemi arasında gerçekleşir (Şekil 2 a) (Weser vd., 2008). Algılayıcıya bağımlı yöntemin genel hali aşağıdaki gibidir:

$$
\vec{P}=\vec{P}_{S}+R_{O G} \cdot R_{P O} \cdot\left\lfloor C_{M}+s \cdot R_{C P} \cdot\left(\vec{p}_{s}-\vec{c}_{s}+\delta \vec{x}\right)\right\rfloor
$$

Burada $\vec{P}$ yer koordinatlarına ait konum vektörünü, $\vec{P}_{S}$ uydunun yer koordinatlarına ait konum vektörünü, $R_{O G}$ yörünge koordinat sisteminden yer koordinat sistemine dönüşümü, $R_{P O}$ uydu koordinat sisteminden yörünge koordinat sistemine dönüşüm, $C_{M}$ kamera koordinat sisteminin uydudaki konumunu ve dönüklüğünü, $s$ ölçeği, $R_{O G}$ kamera koordinat sisteminden uydu koordinat sistemine dönüşümü, $\vec{p}_{s}$ satır koordinatlarına ait vektörü, $\vec{c}_{s}$ doğrusal dizinin kamera koordinat sistemindeki konumunu ve dönüklüğünü, $\delta \vec{x}$ sistematik hata düzeltmelerine ait vektörü temsil etmektedir. Konum, hız, dönüklük gibi yöneltme öğeleri farklı sıklıklarla zamana bağlı olarak elde edildiklerinden zaman ölçme uyumluluğu önemli bir etkendir. Ayrıca yöneltme öğelerinin değerleri doğrusal bir dizinin her bir satırı için birbirinden farklı olacağından uygun bir kestirim yöntemi (Lagrange, doğrusal vb.) ile belirlenmelidir (Riazanoff, 2004).

Algılayıcıya bağımlı yöntemlerde göz önünde bulundurulması gereken diğer bir konu ise fotogrametrik sistemlerde kullanılan mercek sistemlerinden kaynaklanan geometrik bozulmaların kalibrasyon raporları veya kendiliğinden 
kalibrasyon ile giderilmesi gerektiğidir (Dörstel vd., 2003; Fraser, 1997). Uydularda ise genellikle aynalardan oluşan Korsch teleskoplar kullanıldığından olası geometrik bozulmalar önemli ölçüde azaltılmıştır (Grange vd., 2006). Örneğin SPOT-5 için bu bozulma göz ardı edilebilir düzeydedir (Weser vd., 2008).

Yüksek doğrulukla 2/3B konum bilgisi üretmenin mümkün olduğu bu yöntemler algılayıcıya göre farklılık gösterebilmektedir. Bu farklılığın yazılımlara uyarlanması güç olduğundan, bu yöntemlerle hemen hemen aynı doğrulukta sonuçlar veren RFM yöntemi geliştirilmiştir. 1999 yılından beri yüksek çözünürlüklü uzaktan algılama görüntüleri için önerilen genel bir dönüşüm modelidir (OGC, 1999). RFM algılayıcıya bağımlı ve algılayıcıdan bağımsız olmak üzere iki türlüdür. Bu bölümde algılayıcıya bağımlı RFM anlatılacak, algılayıcıdan bağımsız RFM ise Algılayıcıdan Bağımsız Yöntemler başlığında ele alınacaktır. Algılayıcıya bağımlı RFM'ye ait toplam 78 katsayı

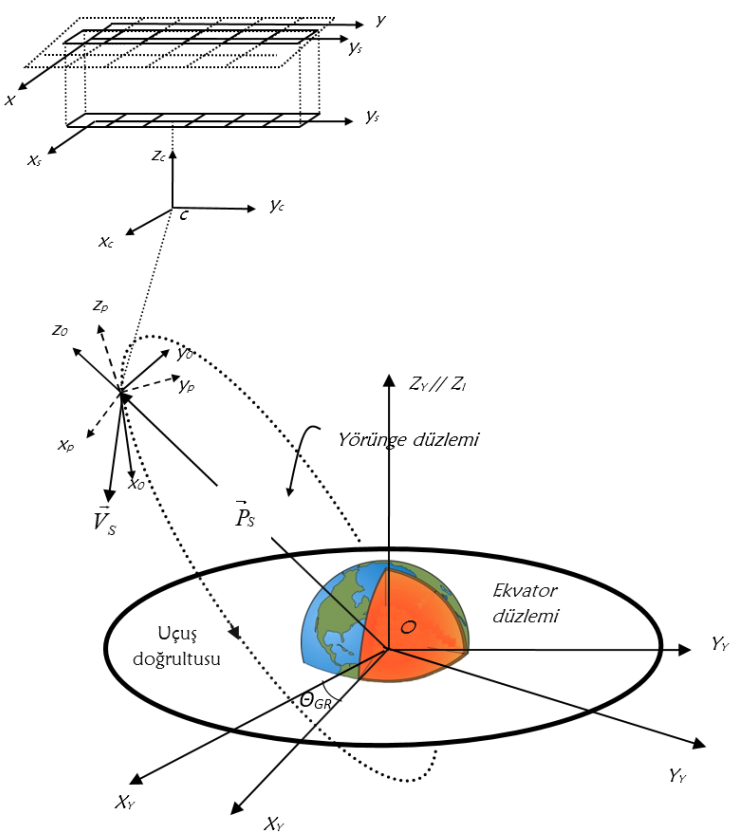

a)Uzaktan algilamada doğrusal dizin görüntï ile yer koordinat sistemi arası dönüşüm

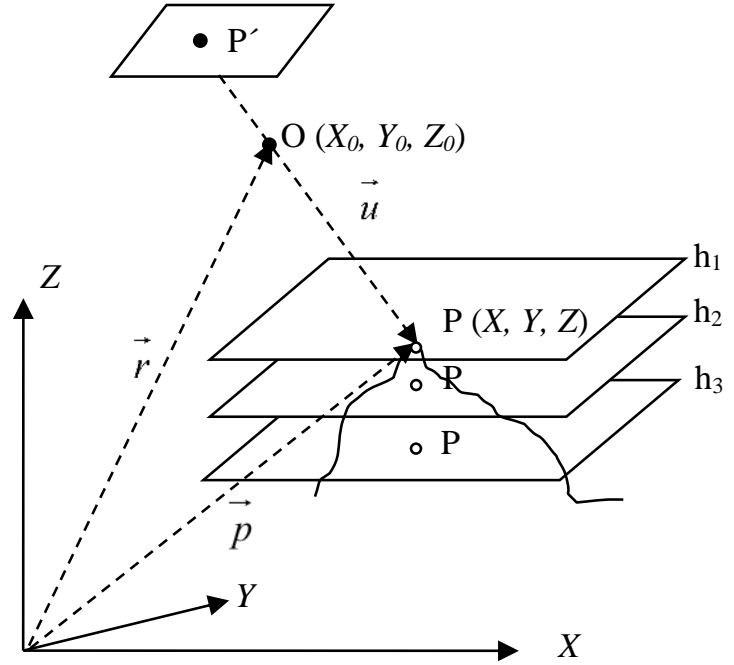

b) RFM katsayılarının (RPC) elde edilmesinin geometrik temeli.

Şekil 2. Fotogrametri ve uzaktan algılamada algılayıcıya bağımlı yöntemler için koordinat sistemleri.

(RPC), (3) numaralı bağıntı ile verilen algılayıcıya bağımlı yöneltme ile her bir görüntü için ayrı ayrı belirlenerek kullanıcıya sunulur (Şekil 2 b). Burada, görüntüde $\mathrm{P}^{\prime}$ ile gösterilen noktanın görüntüdeki karşıllı̆ının (P) konumu, algılayıcıya bağlı bir model ve $\vec{p}=\vec{r}+\vec{u}$ kuralı yardımıyla farklı yükseklik seviyeleri (örneğin $\mathrm{h}_{1}, \mathrm{~h}_{2}$ ve $\mathrm{h}_{3}$ ) için belirlenir. Farklı yükseklik seviyeleri için belirlenmesinin sebebi, bindirmeli (stereo) görüntü veya bölgeye ait yükseklik bilgisi yoksa, P noktasının hangi yükseklik seviyesinde olduğunun bilinememesidir. Böylece, P'nin tüm yüksekliklere göre konumu belirlenir ve bunlar aşağıda verilen eşitliklerde yerine konularak RPC'ler elde edilir. Her yükseklik seviyesi için farklı RPC elde edileceğinden bunların ortalaması alınarak, görüntünün her yükseklik bölgesi için en uygun RPC seti oluşturulmuş olur. RFM'nin bağıntısı aşağıdaki gibidir:

$$
\begin{aligned}
& f=\sum_{g=0}^{m_{g}} \sum_{j=0}^{m_{j}} \sum_{k=0}^{m_{k}} P_{g j k} X_{i}^{g} Y_{i}^{j} Z_{i}^{k} \\
& f_{1}=a_{000}+a_{100} X_{n_{i}}+a_{010} Y_{n_{i}}+a_{001} Z_{n_{i}}+a_{110} X_{n_{i}} Y_{n_{i}}+a_{011} Y_{n_{i}} Z_{n_{i}}+a_{101} X_{n_{i}} Z_{n_{i}}+a_{200} X_{n_{i}}^{2} \\
& +a_{120} X_{n_{i}} Y_{n_{i}}^{2}+a_{300} X_{n_{i}}^{3}+a_{102} X_{n_{i}} Z_{n_{i}}^{2}+a_{021} Y_{n_{i}}^{2} Z_{n_{i}}+a_{201} X_{n_{i}}^{2} Z_{n_{i}}+a_{003} Z_{n_{i}}^{3}
\end{aligned}
$$$$
+a_{020} Y_{n_{i}}^{2}+a_{002} Z_{n_{i}}^{2}+a_{111} X_{n_{i}} Y_{n_{i}} Z_{n_{i}}+a_{030} Y_{n_{i}}^{3}+a_{210} X_{n_{i}}^{2} Y_{n_{i}}+a_{012} Y_{n_{i}} Z_{n_{i}}^{2}
$$

Burada $r, c$ görüntünün sırasıyla satır ve sütununu, altindis $n$ normalleştirme yapıldığını, $O$ ötelemeyi; $s$ ölçeği ve $a, b, c, d$ ise katsayıları (RPC) ifade eder. Buradaki derecelerin toplamı $(g+j+k) \leq 3$ koşulunu sağlamalıdır. Normalleştirme işlemi ile tüm koordinatlar kendi türünde \pm 1 aralığına getirilir ve böylece dengeleme işleminde 
oluşabilecek kötü koşullu durumun önüne geçilmiş olur. İlk yıllarda sadece yerden görüntüye dönüşümü sağlayan RPC'ler verilmekte iken günümüzde görüntüden yere dönüşümü sağlayan RPC'ler de verilmektedir. Nesne koordinatları WGS-84 (World Geodetic System-1984) datumunda ve coğrafi koordinatlar şeklinde olmalıdır. Zira RPC'ler, bu koordinat sisteminde ve türünde GNSS ile elde edilen ögeler yardımıyla hesaplanmaktadır. IKONOS görüntüleri için $b=d$ ve genellikle $b_{1}=d_{1}=1$ 'dir ki kesirli bir yapıya sahip olan RFM ile RPC hesabı yapmak mümkün olabilmektedir.

\subsection{Algılayıcıdan Bağımsız Yöntemler}

Eğer görüntüye ait iç ve dış yöneltme elemanları bilinmiyor veya kullanılmayacaksa bu durumda algılayıcıdan bağımsız yöneltme yöntemleri kullanılabilir. Bunlar i) benzerlik, ii) afin, iii) polinom, iv) afin izdüşüm, v) projektif, vi) DLT (Direct Linear Transformation) ve vii) algılayıcıdan bağımsız RFM yöntemleridir. Yöneltmeyi sağlayan katsayılar YKN yardımıyla hesaplandıklarından bu noktaların doğruluğu, sayısı ve dağılımına doğrudan bağlıdırlar. Bunlardan benzerlik, polinom ve afin izdüşüm yöntemi, optik görüntülemenin temel ilkesi olan merkezî iz düşümden ziyade dik iz düşüm için kullanılan yöntemlerdir. Uzaktan algılama uygulamalarında bu yöntemlerin kullanılmalarının temel nedeni, uydu görüntülerinin kapladıkları alana oranla çok dar bir açıyla görüntü almasıdır. Bu durumda merkezi iz düşümde birbirine yaklaşan iz düşüm doğruları, uzaktan algılama görüntülerinde paralel kabul edilebilir. (Okamoto, 1992). Aşağıda sırasıyla bu yöntemler tanitılmaktadır.

\subsubsection{Benzerlik Dönüşümü}

Benzerlik dönüşümü, 2B koordinat sistemleri arasındaki dönüşümü sağlamaktadır. $\mathrm{Bu}$ koordinat sistemlerinin eksenleri birbirine diktir ve iki koordinat sistemi arasındaki dönüşümde tek bir açı ve ölçek söz konusudur. Bu durumda iki koordinat sistemi arasındaki dönüşüm:

$$
\left[\begin{array}{c}
r_{i} \\
c_{i}
\end{array}\right]=\left[\begin{array}{c}
X_{0} \\
Y_{0}
\end{array}\right]+s\left[\begin{array}{cc}
\cos \propto & -\sin \propto \\
\sin \propto & \cos \propto
\end{array}\right]\left[\begin{array}{c}
X_{i} \\
Y_{i}
\end{array}\right]=\left[\begin{array}{l}
a_{00}+a_{10} X_{i}-a_{01} Y_{i} \\
b_{00}+a_{01} X_{i}+a_{10} Y_{i}
\end{array}\right]
$$

şeklinde yazılabilir. Burada $a, b$ katsayıları ifade etmektedir. Dört ögeye sahip benzerlik dönüşümünün çözümü için her iki koordinat sisteminde, koordinatları bilinen en az iki YKN'ye ihtiyaç vardır. Benzerlik dönüşümü şekil koruyan bir yöntemdir. Yani geometrik bir şekle sahip alanlar sabit oranda değişir ve dönüşüm sonrasındaki şekil esas şekline benzerdir. Benzerlik dönüşümde açı değerleri korunur (Kurt, 2002). Bu durum, dönüşümde şeklin korunumunu zorlayıcı bir özellik olduğundan, uydu görüntüleri için benzerlik dönüşümü kullanılarak elde edilen hata değeri diğer yöntemlere göre daha yüksek olmaktadır (Topan vd., 2016).

\subsubsection{Afin Dönüşüm}

Afin dönüşümde, 2B iki koordinat sistemi arasındaki dönüşüm iki öteleme, iki açı ve bir ölçek yardımıyla gerçekleştirilir. $\mathrm{Bu}$ nedenle afin dönüşüm, her iki eksen için farklı ölçek ve dönme açısına sahiptir. Böylece, görüntülerde satır ve sütun yönünde farklı geometrik bozulmaları dikkate aldığı için afin dönüşüm uzaktan algılama ve fotogrametride kullanılabilir (Turgut ve İnal, 2003). Afin dönüşümünde bir doğru dönüşüm sonrası, yine bir doğrudur. Dolayısıyla her iki koordinat sistemindeki iki doğru parçasının oranı ve paralellikleri dönüşüm sonrası da aynı kalır. Afin dönüşümün matematik modeli:

$$
\left[\begin{array}{l}
r_{i} \\
c_{i}
\end{array}\right]=\left[\begin{array}{l}
X_{0} \\
Y_{0}
\end{array}\right]+\left[\begin{array}{cc}
s_{1} & 0 \\
0 & s_{2}
\end{array}\right]\left[\begin{array}{cc}
\cos w & -\sin \varphi \\
\sin \varphi & \cos w
\end{array}\right]\left[\begin{array}{l}
X \\
Y
\end{array}\right]=\left[\begin{array}{c}
a_{00}+a_{10} X_{i}+a_{01} Y_{i} \\
b_{00}+b_{10} X_{i}+b_{01} Y_{i}
\end{array}\right]
$$

şeklindedir. Burada $s_{1}$ ve $s_{2}$ iki eksen yönündeki ölçeği, $w$ ve $\varphi$ ise iki eksen etrafındaki farklı dönme açılarını temsil etmektedir. Toplam altı ögenin çözümü için en az üç YKN'ye ihtiyaç vardır. Bu yöntem, uzaktan algılamada sıklıkla kullanılan band çakıştırma işleminde tercih edilen bir dönüşüm yöntemidir.

\subsubsection{Polinom Dönüşümü}

Polinom dönüşümü de 2B dönüşüm için kullanılabilen bir dönüşümdür (Zoej, 1997). Polinom dönüşümünün genel bağıntısı aşağıdaki gibidir.

$$
r_{i}=\sum_{j=0}^{m} \sum_{k=0}^{m} a_{j k} X_{i}^{j} Y_{i}^{k}, \quad c_{i}=\sum_{j=0}^{m} \sum_{k=0}^{m} b_{j k} X_{i}^{j} Y_{i}^{k}
$$

Burada $j+k \leq m$ olması gerektiği ve polinom dönüşümünün derecesinin $(m)$ kuramsal olarak sonsuz bir değer olabileceği hatırlatılmalıdır. Ancak bu değer uygulamada 5 ile sınırlandırılmaktadır (Cam, 2018). Her bir katsayının görüntünün satır ve sütun $(r, c)$ koordinatlarına olan geometrik etkisi Petrie ve Kennie (1990) tarafından tanımlanmıştır (Zoej'den 1997). Afin dönüşüm aslında birinci derece bir polinom dönüşümü, benzerlik dönüşümü de afin dönüşümün özel bir halidir (tek bir ölçek ve dönme açısı kullanımı durumudur). İkinci ve daha yüksek dereceden dönüşümler, görüntüdeki doğrusal olmayan bozulmaların düzeltilmesi için kullanılmaktadır. Polinom derecesine göre katsayıların toplam adedi $n_{k}=(m+1)(m+2)$ olacağından, gerekli YKN sayısı en az $n_{Y K N}=n_{k} / 2$ adet olacaktır. 


\subsubsection{Afin İzdüşüm Dönüşümü}

3B nesne uzayının 2B görüntü uzayına izdüşümü afin izdüşüm yöntemiyle modellenebilir (Yamakawa, 2004). Bu dönüşüme yükseklik düzeltmesi getiren afin dönüşüm adı da verilmektedir (Büyüksalih vd., 2003). Yukarıda anlatılan yöntemlerden farklı olarak, YKN'lerin yükseklik değeri de dikkate alınarak yüksek nesnelerin görüntü uzayındaki kayıklığı bu dönüşüm ile modellenmeye çalışılmaktadır. Bu dönüşümün matematik modeli aşağıdaki gibidir.

$$
\begin{aligned}
& r_{i}=a_{000}+a_{100} X_{i}+a_{010} Y_{i}+a_{001} Z_{i} \\
& c_{i}=b_{000}+b_{100} X_{i}+b_{010} Y_{i}+b_{001} Z_{i}
\end{aligned}
$$

Bu model, büyük bakış doğrultusu ve yavaşlatma etkisi ile görüntülemeden kaynaklanan geometrik bozulmaları gidermek için ek katsayılar kullanılarak QuickBird OrthoReady Standard ve IKONOS Geo görüntüleri için aşağıdaki gibi uyarlanmıştır (Jacobsen, 2003):

$$
\begin{aligned}
& r_{i}=a_{000}+a_{100} X_{i}+a_{010} Y_{i}+a_{001} Z_{i}+a_{101} X_{i} Z_{i}+a_{011} Y_{i} Z_{i} \\
& c_{i}=b_{000}+b_{100} X_{i}+b_{010} Y_{i}+b_{001} Z_{i}+b_{101} X_{i} Z_{i}+b_{011} Y_{i} Z_{i}
\end{aligned}
$$

Ancak OrbView-3 görüntülerinin birbirine paralel olmayan kenarlara sahip olmasından kaynaklanan geometrik etkiyi gidermek için iki ek katsayı daha eklenerek aşağıdaki gibi yazılabilir (Büyüksalih, 2006):

$$
\begin{aligned}
& r_{i}=a_{000}+a_{100} X_{i}+a_{010} Y_{i}+a_{001} Z_{i}+a_{101} X_{i} Z_{i}+a_{011} Y_{i} Z_{i}+a_{200} X_{i}^{2} \\
& c_{i}=b_{000}+b_{100} X_{i}+b_{010} Y_{i}+b_{001} Z_{i}+b_{101} X_{i} Z_{i}+b_{011} Y_{i} Z_{i}+b_{110} X_{i} Y_{i}
\end{aligned}
$$

\subsubsection{Projektif Dönüşüm}

Projektif dönüşüm, fotogrametride en genel dönüşüm modelini içermektedir. İz düşüm düzlemleri birbirlerine paralel olabilir, kesişebilir veya merkezî bir iz düşüm söz konusu olabilir. Bu durumlarda ve iz düşüm sistemleri farklı olan koordinat sistemlerinin dönüşümlerinde kullanılmaktadır (Yaşayan, 1978). 2B afin dönüşüm, projektif dönüşümün özel bir durumudur. Projektif dönüşüm bağıntısı

$$
r_{i}=\frac{a_{00}+a_{10} \cdot X_{i}+a_{01} \cdot Y_{i}}{1+c_{10} \cdot X_{i}+c_{01} \cdot Y_{i}}, c_{i}=\frac{b_{00}+b_{10} \cdot X_{i}+b_{01} \cdot Y_{i}}{1+c_{10} \cdot X_{i}+c_{01} \cdot Y_{i}}
$$

şeklindedir. Burada 2B koordinat sistemleri arasındaki bir dönüşüm söz konusu olduğundan, 3B nesne uzayından 2B görüntü uzayına geçiş, projektif dönüşüme benzer bir şekilde DLT yöntemiyle gerçekleştirilmektedir.

\subsubsection{DLT}

DLT yöntemi, Abdel-Aziz ve Karara (1971) tarafından geliştirilen ve (1) numaralı bağıntı ile verilen eşdoğrusallık eşitliklerinin yeniden düzenlenerek, iç ve dış yöneltme ögelerine ihtiyaç duymadan dönüşüm sağlayan bir yöntemdir ve bağıntısı aşağıdaki gibidir:

$$
\begin{aligned}
& f_{1}=a_{000}+a_{100} \cdot X_{i}+a_{010} \cdot Y_{i}+a_{001} \cdot Z_{i} \\
& f_{2}=b_{000}+b_{100} \cdot X_{i}+b_{010} \cdot Y_{i}+b_{001} \cdot Z_{i} \\
& f_{3}=1+c_{100} \cdot X_{i}+c_{010} \cdot Y_{i}+c_{001} \cdot Z_{i} \\
& r_{i}=\frac{f_{1}}{f_{3}} \quad c_{i}=\frac{f_{2}}{f_{3}}
\end{aligned}
$$

Bu yöntem, iç ve dış yöneltme elemanlarına gereksinim duymadan eşdoğrusallık ilkesi ile dönüşüm yapmaya olanak sağladığından özellikle bilgisayarla görme işlemlerinde çokça tercih edilmektedir.

\subsubsection{RFM}

Algılayıcıya bă̆ımlı ve algılayıcıdan bă̆ımsız RFM arasındaki fark, RPC'lerin ilk yöntemde algılayıcıya bă̆ımlı bir yöntemle Şekil 2 b'deki gibi elde edilmesi, ikinci yöntemde ise YKN'ları ile hesaplanmasıdır. Dolayısıyla algılayıcıdan bağımsız RFM, YKN'lerin doğruluğuna, sayısına ve dağılımına doğrudan bağlıdır. Her iki tür RFM için (4 a-e) ile verilen bağıntı geçerlidir.

\section{DENGELEME}

Algılayıcı yöneltmesinde dengeleme işlemi önemli bir adımdır. Zira hem görüntü çeşitli bozulmalara sahiptir, hem de algılayıcıya bağımlı yöntemin parametreleri hatalıdır ve düzeltilmeleri gerekir. Bunun yanında algılayıcıdan bă̆ımsız bir yöntemin katsayıları da yine dengeleme işlemi ile belirlenir. Dengelemede EKK (En Küçük Kareler) yöntemi kullanılabileceği gibi kötü koşul durumunda düzenlileştirme yöntemleri de kullanılmaktadır. Dolaylı ölçüler 
dengelemesi veya koşullu dengeleme gibi farklı dengeleme yöntemleri dayalı veya serbest dengeleme olarak uygulanabilir. Ayrıca parametre anlamlılık testinin yapılması, gereksiz parametrelerin/katsayıların ayıklanmasını sağlayarak işlem kolaylığı sağlar. Bunun yanında uyuşumsuz ölçü testinin yapılması, ölçü kümesine uymayan gözlemlerin ayıklanarak sonuç doğruluğun artmasını sağlayacaktır.

\subsection{Dolaylı Ölçüler Dengelemesi}

Bakış açılarının $(\psi)$ kullanıldığı algılayıcıya bağımlı yöneltme yöntemlerinin dışında kalan tüm yöntemlerde dolaylı ölçüler dengelemesinin kullanıldığı görülmektedir. Burada görüntü ve nesne koordinat sistemleri arası dönüşümün genel bağıntısı:

$$
(r, c)_{i}=\mathrm{F}\left\{P_{j},(X, Y, Z)_{i}\right\}
$$

şeklindedir. Burada F dönüşüm modelini, $P$ dönüşüm katsayısını veya ögesini, $i$ ve $j$ ise sırasıyla YKN ve ögelerle/katsayılarla ilgili olan indisleri, üst çizgi ise dengeli koordinatları ifade etmektedir. Algılayıcıya bağımlı bir modelde $P$ iç ve dış yöneltme ögelerini, algılayıcıya bağımlı RFM'de RPC'leri veya algılayıcıdan bağımsız bir modelde YKN'ları yardımıyla belirlenen dönüşüm katsayılarını ifade etmektedir. YKN'larının nesne koordinatları hatasız (dengeli) kabul edilir ve 2B bir dönüşüm yönteminde $Z$ koordinat bileşeni kullanılmaz. Dengeleme işleminde hem görüntü koordinatlarına $(r, c)$ hem de ögelere/katsayılara $(P)$ getirilecek düzeltme değerleri döngüsel olarak aşağıdaki gibi hesaplanır.

$$
\begin{aligned}
& \underline{\bar{L}}=\underline{L}+\underline{v}=\left.\underline{L}\right|_{0}+\underline{A d P} \\
& \underline{d P}=\left(\underline{A}^{T} \underline{A}\right)^{-1} \underline{A}^{T}\left(\underline{L}-\left.\underline{L}\right|_{0}\right) \\
& \underline{\bar{P}}=\left.\underline{P}\right|_{0}+\underline{d P} \\
& \underline{v}=\left.\underline{L}\right|_{0}-\underline{L}+\underline{A} \underline{d P} \\
& m_{0}= \pm \sqrt{\frac{\underline{v}^{T} \underline{v}}{f}}
\end{aligned}
$$

Burada sıfır (0) katsayıların yaklaşık değerleri ile hesaplanan görüntü koordinatlarını, $d P$ katsayılara getirilecek düzeltmeyi (dengeleme bilinmeyeni), $\underline{A}$ dengeleme bilinmeyenlerinin $(d P)$ katsayılar (Jakobiyen) matrisini, $m_{0}$ birim ağırlıklı ölçünün koh'unu, $v$ ölçülere (görüntü koordinatlarına) getirilecek düzeltmeleri, $f$ ise serbestlik derecesini ifade etmektedir ve $f=2 n-u\left(n\right.$ : YKN sayısı, $u$ : öge/katsayı adedi) şeklinde hesaplanır. Dengeleme sonucunda $\left[v^{T} \underline{v}\right]=$ min ve $m_{0} \leq 1$ piksel olması beklenir (Leprince vd., 2007). Algılayıcıdan bağımsız dönüşüm yöntemleri ile yapılan işlemlerde katsayıların yaklaşık değeri bilinmediğinden (16) bağıntısından ilk döngü için $\underline{P}=\underline{d P}$ eşitliği yazılabilir. Ancak diğer döngülerde $\left.\underline{P}\right|_{0}=\underline{P}$ kabulü yapılarak dengeleme hesabı tekrarlanır. (13) numaralı bağıntıda görüntü koordinatları yöneltme ögelerinin/katsayılarının bir işlevi olarak düşünülmektedir. Oysa (1) ve (2) numaralı bağıntılarda nesne koordinatları görüntü koordinatlarının ve yöneltme ögelerinin bir işlevi olarak ele alınmıştır. Dolaylı ölçüler dengelemesinde (13) numaralı eşitlikte görüntü koordinatları ölçü, yöneltme ögelerinin yaklaşık değerlerine getirilecek düzeltmeler $(\underline{d P})$ dengeleme bilinmeyeni olarak kabul edilerek dengeleme işlemi gerçekleştirilir. Böylece görüntü ile nesne koordinat sistemleri arasındaki dönüşüm işlemi, düzeltilmiş değerler yardımıyla gerçekleştirilir.

\subsection{Koşullu Ölçüler Dengelemesi}

Günümüzde algılayıcıya bağımlı yöntemlerin iç yöneltme elemanlarını bakış açısı ( $\psi)$ kullanıldığı durumda dönüşüm bağıntısı

$$
\begin{aligned}
& F_{\psi_{y}}=\frac{r_{11}\left(X-X_{s}\right)+r_{12}\left(Y-Y_{s}\right)+r_{13}\left(Z-Z_{s}\right)}{r_{31}\left(X-X_{s}\right)+r_{32}\left(Y-Y_{s}\right)+r_{33}\left(Z-Z_{s}\right)}-\tan \left(\psi_{y}\right)=\frac{f_{1}}{f_{3}}-\tan \left(\psi_{y}\right)=0 \\
& F_{\psi_{x}}=\frac{r_{21}\left(X-X_{s}\right)+r_{22}\left(Y-Y_{s}\right)+r_{23}\left(Z-Z_{s}\right)}{r_{31}\left(X-X_{s}\right)+r_{32}\left(Y-Y_{s}\right)+r_{33}\left(Z-Z_{s}\right)}+\tan \left(\psi_{x}\right)=\frac{f_{2}}{f_{3}}+\tan \left(\psi_{x}\right)=0
\end{aligned}
$$

şeklinde bir koşul denklemi olarak ele alınmaktadır. Koşullu ölçüler dengelemesi (Gauss-Helmert yöntemi) uygulandiğında fonksiyonel model

$$
\underline{A} \cdot \underline{d P}+\underline{B} \cdot \underline{v}+\underline{w}=\underline{0}
$$

şeklindedir. Burada $\underline{A}$ ve $\underline{B}$ sırasıyla dış yöneltme ögelerine ve ölçülere ait Jakobiyen matrisi ve $\underline{w}$ de kapanma artıklarını tanımlamaktadır. $\underline{A}$ ve $\underline{B}$ matrisleri (19) bağıntısıyla verilen ve doğrusal olmayan eşitliklerin uygun bir yöntemle (Taylor serisi gibi) doğrusallaştırmasıyla elde edilir. Dengeleme bilinmeyenleri $(d P)$ aşağıdaki gibi 
hesaplanarak (16) bağıntısındaki gibi ögelerin yaklaşık değerlerine $\left(\left.P\right|_{0}\right)$ eklenir ve böylece dengelenmiş ögeler bulunur:

$\underline{d P}=-\left(\underline{A}^{T}\left(\underline{B} \underline{B}^{T}\right)^{-1} \underline{A}\right)^{-1} \underline{A}^{T}\left(\underline{B} \underline{B}^{T}\right)^{-1} \underline{w}$

Ölçülere ait düzeltmeler de aşağıdaki şekilde hesaplanarak ölçülere eklenir ve böylece dengeli ölçüler elde edilir:

$\underline{v}=B^{T}\left(\underline{B} \underline{B}^{T}\right)^{-1}(\underline{A} \underline{d P}+\underline{w})$

Elde edilen dengeli ögelerin ve ölçülerin (19) eşitliğiyle verilen koşulu sağlayıp sağlamadığının $\left(F(\bar{L}, \bar{P})_{=}^{?} 0\right)$ kontrol edilmesi gerekir. Bu şart sağlanıncaya dek dengeli parametreler ve ölçülerle yeniden dengeleme işlemine tabi tutulur.

\subsection{Demet Dengeleme}

Demet dengelemede amaç birden fazla görüntüye ait ölçülerin ve ögelerin birlikte dengelenmesidir. Ayrıca bağlama/denetim noktalarının yaklaşık yer koordinatları da o noktalara ait ögeler olarak kabul edilir ve bu koordinatlara ait düzeltme değerleri de hesaplanır. Bu durumda (20) eşitliği:

$\left[\begin{array}{ccc}\underline{A}_{1} & \cdots & \underline{0} \\ \vdots & \ddots & \vdots \\ \underline{0} & \cdots & \underline{A}_{m}\end{array}\right]\left[\begin{array}{c}\frac{d P_{1}}{\vdots} \\ d P_{m}\end{array}\right]+\left[\begin{array}{ccc}\underline{B}_{1} & \cdots & \underline{0} \\ \vdots & \ddots & \vdots \\ \underline{0} & \cdots & \underline{B}_{m}\end{array}\right]\left[\begin{array}{c}\underline{v}_{1} \\ \vdots \\ \underline{v}_{m}\end{array}\right]+\left[\begin{array}{c}\underline{w}_{1} \\ \vdots \\ \underline{w}_{m}\end{array}\right]=\underline{0}$

şeklinde yazılır. Burada $m$ toplam görüntü sayısını ifade etmektedir. Bu sayede gerek YKN/BDN'lerinin dengeli koordinatları ile ölçülerek elde edilen koordinatları arasındaki farktan sonuç doğruluklar elde edilebilir.

\subsection{Kötü Konum ve Kötü Koșul Durumları}

Dengeleme işleminde kötü konum ve kötü koşul durumları ile karşılaşmak olasıdır. Döngüsel işlemlerde ıraksamaya veya dengeleme bilinmeyenlerinin $(d P)$ ve dolayısıyla ölçülere getirilecek düzeltmelerin $(v)$ olması gerekenden çok farklı değerlerle hesaplanarak sonuç doğruluğun yanlış hesaplanmasına yol açabilirler. Kötü konum sorununa örnek dönüşüm bağıntısının yeterli düzeyde dönüşümü temsil etmemesi verilebilri. Kötü koşul sorununa örnek ise ögelerin/katsayıların kendi aralarında veya ölçülerle arasındaki olası korelasyondan veya $\underline{A}^{T} \underline{A}$ simetrik matrisinin köşegen elemanlarının sıfır veya sıfıra yakın olmasından kaynaklanan kötü kondisyon sorunu gösterilebilir (Tao ve Hu, 2001; Topan ve Maktav, 2014). Matris tersinin sağlıklı alınamasına neden olan bu sorunların çözümü için Tikhonov düzenlileştirmesi, indirgeme veya genelleştirilmiş matris tersi (Moore-Pensore veya Pseudo ters) gibi faklı düzenlileştirme yöntemleri uygulanmaktadır. Bununla birlikte, her bir koordinat türü \pm 1 aralığına getirilerek işlem yapilırsa bu sorun giderilebilir.

\subsection{Uyuşumsuz Öıçülerin ve Anlamsız Ögelerin Belirlenmesi}

YKN'larının görüntü koordinatları ölçü olarak kabul edildiğinden, görüntü üzerinde YKN işaretlenirken yapılacak hatanın belirli bir sınırda olması gerekir. Bu sınırı aşan durumlarda ölçü uyuşumsuz kabul edilir. Bunun için normal dağılım, Pope (Tau dağılımı) veya t-student yöntemi kullanılabilir (Cam, 2018).

Bazı ögeler/katsayılar dengelemede bilinmeyen olarak dikkate alınmayabilir (Ghilani ve Wolf, 2006). Böyle bir durumda, algılayıcıya bağımlı bir ögenin yaklaşık değerine düzeltme getirilmesine gerek kalmazken algılayıcıdan bağımsız bir yöntemde ise o katsayı kullanılmayabilir. Böylece gereğinden fazla öge/parametre kullanımından kaçınılarak hem serbestlik derecesi arttırılmış hem de olası kötü koşul sorununun önüne geçilmiş olur (Moghaddam vd., 2018). Klasik yaklaşımların yanısıra son yıllarda anlamsız RPC'lerin bulunması için genetik optimizasyon yöntemleri de kullanılmaktadır (Naeini vd., 2017; Valadan Zoej vd., 2007). Ayrıca bir ögenin anlamsız olması, ona getirilecek düzeltmenin sonuç doğruluğa katkısının önemsenmeyecek derecede olduğu anlamına da gelmektedir (Topan ve Maktav, 2014).

\subsection{Yardımcı Veriler ve Sonuç Doğruluk Araştırması}

Dengeleme işlemi için genellikle YKN'ları kullanılmaktadır. Böylece (1) numaralı bağıntı dışında kalan algılayıcıya bağıml yöntemlerde ögelere/RPC'lere düzeltme getirilebilir veya algllayıcıdan bağımsız yöntemde katsayılar hesaplanabilir. YKN seçimi dönüşüm başarımını etkilediğinden olabildiğince doğru yapılmalıdır (Kapnias vd., 2008; Topan vd., 2007). Günümüzde YKN yerine görüntüdeki çizgisel özellikli nesneleri (yol orta/kenar çizgisi, bina kenarı vb.) kullanan yöntemler de mevcuttur (Habib vd., 2003; Li ve Shi, 2014; Yavari vd., 2018). Kuramsal olarak (1) numaralı bağıntı dışındaki algılayıcıdan bağımsız yöntemler YKN veya çizgisel özellikteki nesnelere ihtiyaç duymazlar. Ancak hatalı olduğu varsayılan ögelerin düzeltilmesi için yine de bunların kullanılması gerekir. Haliyle özellikle bunların sayısı/miktarı ve dağılımına bağımlılıkları algılayıcıya bağımlı yöntemlere oranla daha azdır (Topan ve Maktav, 2014).

Dönüşüm doğruluğu farklı yöntemlerle incelenebilir. BDN'ler, YKN'ler ile aynı özelliklere sahip olan ve dönüşüm işlemi sonunda YKN'ler dışında kalan bölgelerde elde edilecek doğruluğun hesaplanmasında kullanılan noktalardır. 
Algılayıcıdan bă̆ımsız yöntemlerde dengeleme hesabına katkısı yokken, algılayıcıya bağımlı yöntemin kullanıldığı demet dengeleme hesabında yer almaktadır. BDN'ler ile elde edilen doğruluk sadece kendi bulunduğu noktayı temsil ettiğinden ve YKN'lerin bir kısmının BDN olarak kullanılmasının YKN sayısını azaltması gibi sakıncalar nedeniyle eğer elde yatay ve düşey doğruluğu bilinen bir SYM varsa, bu sayede tüm görüntü için geçerli bir doğruluk araştırması yapilabilir (Moghaddam vd., 2018; Sertel vd., 2007; Topan, 2013, 2014; Topan ve Kutoglu, 2009; Topan vd., 2014; Topan vd., 2013).

Bindirmeli görüntülerden de elde edilebilen SYM, hem ortogörüntü üretiminde ilgi alanına ait yükseklik bilgisi sunan, hem de doğruluk araştırmasında YKN'ye gereksinimi ortadan kaldıran bir veri türüdür (Chen vd., 2017).

\section{2/3B KOORDINAT BILGISII ELDE ETME}

Dengeleme işlemi ile görüntü ve nesne koordinat sistemleri arası olası en hatasız dönüşüm sağlanmış olur. Böylece görüntülerden 2 veya 3 boyutlu koordinat bilgisi elde edilebilir. Ortogörüntüler $2 \mathrm{~B}$ koordinatları, SYM ise 3B koordinatları sunan birer üründür. Bir ortogörüntü, görüntü alımı sırasında algılama ve taşıyıcı sistem geometrisinden kaynaklanan görüntülerdeki eğiklik ve dönüklük gibi hataların giderilmesi ve yükseklik farklarından kaynaklanan yatay kayıklığın da en az düzeye indirilmesi ile elde edilen görüntü veya görüntü mozaiği olarak tanımlanmaktadır (Ottavianelli ve Vescovi, 2018). İki tür ortogörüntü üretimi söz konusudur. Bunlardan birincisi, görüntü koordinatlarından nesne koordinatlarının elde edildiği doğrudan yöntem, diğeri ise nesneden görüntü koordinatlarının elde edildiği dolaylı yöntemdir (Konecny, 1979). Doğrudan yöntemde, örneğin (1)-(3) numaralı bağıntılarla verilen görüntüden nesneye olan ışın yolu ve SYM'den elde edilen yükseklikler döngüsel olarak şu şekilde kullanılır: Önce $Z_{0}=0$ kabul edilerek yatay koordinatlar hesaplanır. Sonra hesaplanan bu yatay koordinatlara SYM'de karşılık gelen $Z_{I}$ bulunur. Bu değer kullanılarak yatay koordinatlar ve bunlara karşılık gelen $Z$ değeri hesaplanır. Böylece her döngüde hesaplanan yatay koordinatlar arası fark belirli bir eşik değere ulaşana dek döngü sürdürülür (Şekil 3 a). Dolaylı yöntemde ise (13) numaralı bağıntıda olduğu gibi nesneden görüntüye olan dönüşüm yardımıyla SYM'nin her bir pikseline karşılık gelen görüntü koordinatları hesaplanır ve yeniden örnekleme işlemi ile gri değer ataması yapilır (Cam, 2018).
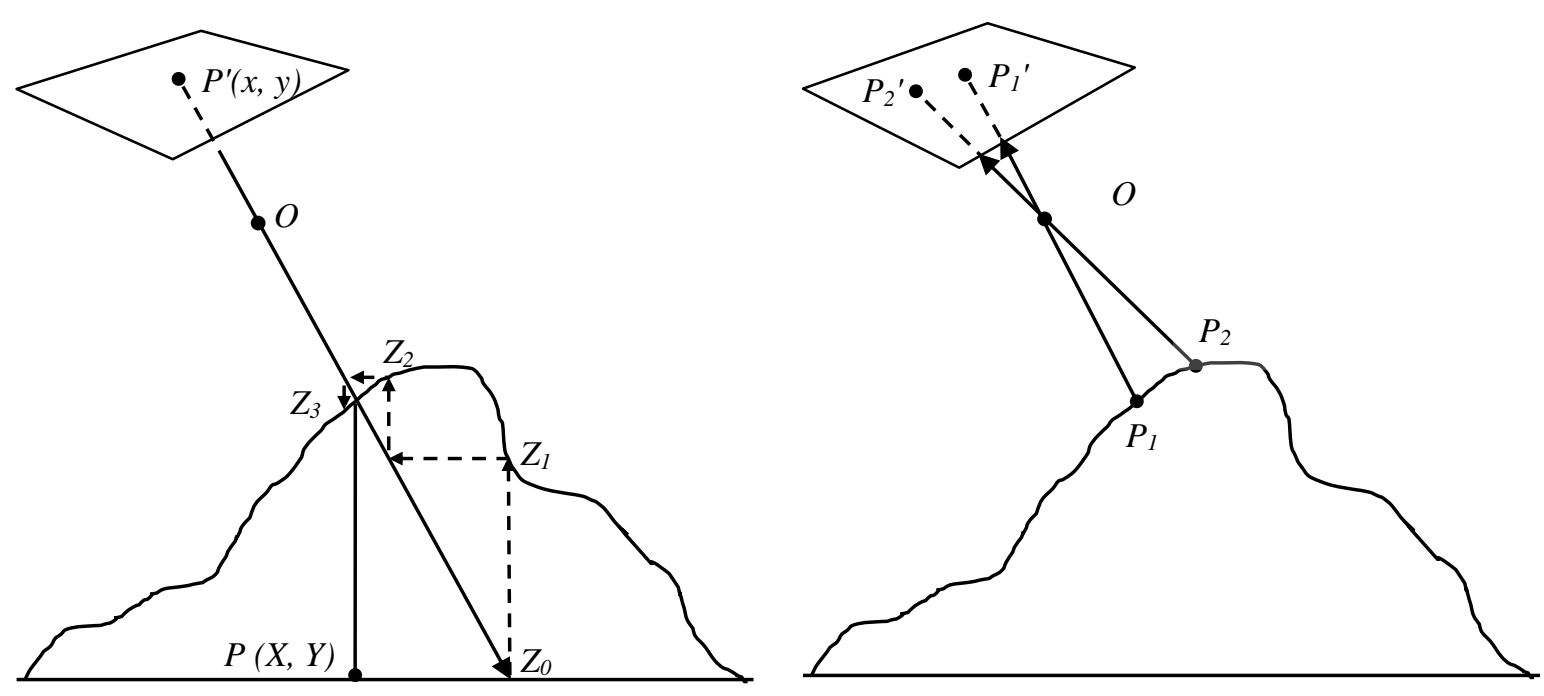

Şekil 3. Ortogörüntü üretiminde doğrudan (solda) ve dolaylı (sağda) yöntemler.

Eğer bindirmeli görüntüler mevcutsa 3B koordinatları hesaplamak olasıdır (Okamoto, 1992; Poli, 2005). İki görüntüden de aynı nesne koordinatları elde edilmesi gerektiğinden örneğin (1) numaralı eşitlik yardımıyla

$\left[\begin{array}{c}X \\ Y \\ Z\end{array}\right]=\left[\begin{array}{c}X_{0} \\ Y_{0} \\ Z_{0}\end{array}\right]_{1}+m_{1} \underline{R}_{1}\left[\begin{array}{c}x-x_{o} \\ y-y_{o} \\ -c\end{array}\right]_{1}=\left[\begin{array}{c}X_{0} \\ Y_{0} \\ Z_{0}\end{array}\right]_{2}+m_{2} \underline{R}_{2}\left[\begin{array}{c}x-x_{o} \\ y-y_{o} \\ -c\end{array}\right]_{2}$

şeklinde yeniden yazılabilir. Bu bağıntı aşağıdaki gibi düzenlenirse:

$\left[\underline{R}_{1}\left[\begin{array}{c}x-x_{o} \\ y-y_{o} \\ -c\end{array}\right]_{1}-\underline{R}_{2}\left[\begin{array}{c}x-x_{o} \\ y-y_{o} \\ -c\end{array}\right]_{2}\right] \cdot\left[\begin{array}{l}m_{1} \\ m_{2}\end{array}\right]=\left[\left[\begin{array}{c}X_{0} \\ Y_{0} \\ Z_{0}\end{array}\right]_{2}-\left[\begin{array}{c}X_{0} \\ Y_{0} \\ Z_{0}\end{array}\right]_{1}\right]$ 
$\underline{A} \cdot \underline{m}=\underline{b}$

$\underline{m}=\left(\underline{A}^{T} \underline{A}\right)^{-1} \underline{A}^{T} \underline{b}$

$m_{1}$ ve $m_{2}$ değerleri hesaplanarak (24) numaralı bağıntı ile nesne koordinatları hesaplanabilir. Burada karşılıklı görüntü koordinatlarının görüntü eşleme yöntemleri ile hesaplanması gerekmektedir.

\section{SONUÇLAR}

Günümüzde görüntülerden daha fazla oranda ve giderek artan doğruluklarda konum bilgisi elde edilmektedir. Bu durum, hem algılayıcıların geliştirilmesini hem de farklı dönüşüm modellerinin farklı uygulamalar için kullanılmasını gerekli kılmaktadır. Doğrudan konuma bağlı bilginin kullanıldığı uygulamaların yanında çevre, ormancılık, tarım, peyzaj, şehir ve bölge planlama, arkeoloji, savunma gibi pek çok alanda birer altlık olarak kullanılan görüntü temelli ürünlerin uygulama başarısına katkısını etkileyen algılayıcı yöneltmesi, yöntemin yapısı, yöntemde kullanılan ögelerin/katsayıların neler olduğu ve doğrulukları, YKN ve SYM gibi ek veriler ve bunların kalitesi, dengelemede kullanılan yaklaşım, kötü konum ve kötü koşul durumlarının oluşup oluşmadığı, uyuşumsuz ölçülerin ve anlamsız ögelerin/katsayıların ayıklanması ve sonuç doğruluğun nasıl belirlenebileceği gibi pek çok bileşenle birlikte ele alınması gereken önemli bir konudur. Tüm bu bileşenlerin sonuçlar üzerindeki etkisi ne kadar kontrol altında tutulursa, görüntülerden konum bilgisi elde etme başarımı da o derece artacaktır. Bu bildirinin, Ülkemizde bu konularda araştırma ve uygulama yapanlara yardımcı olması arzu edilmektedir.

\section{KAYNAKLAR}

Abdel-Aziz, Y.I. ve Karara, M., 1971. Direct Linear Transformation from Comparator Co-ordinates into Objectspace Co-ordinates in Close-range Photogrammetry. American Society of Photogrametry Symposium on CloseRange Photogrammetry, syf: 420-475.

Büyüksalih, G., Akcin, H., Jacobsen, K., 2006. Geometry of OrbView-3 Images. ISPRS Topographic Mapping From Space (with Special Emphasis on Small Satellites), Ankara, Turkey.

Büyüksalih, G., Oruç, M. ve Koçak, G., 2003. Geometric Accuracy Testing of Ikonos Geo-Product Mono Imagery Using Different Sensor Orientation Models. Turkish Journal of Engineering and Environmental Sciencies, 27(2003): $347-360$

Cam, A., 2018. Algılayıcan Bağımsız Dönüşüm Yöntemleri İle Üretilen Ortogörüntülerin Konum Doğruluğunun Belirlenmesi. Bülent Ecevit Universitesi, Zongudlak. 61 sayfa.

Chen, X., Zhang, B., Cen, M., Guo, H., Zhang, T. ve Zhao, C., 2017. SRTM DEM-Aided Mapping Satellite-1 Image Geopositioning Without Ground Control Points. IEEE Geoscience and Remote Sensing Letters, 14(11): 21372141 .

Dörstel, C., Jacobsen, K. ve Stallmann, D., 2003. DMC-photogrammetric accuracy-calibration aspects and generation of synthetic DMC images. Optical, 1: 74-82.

Fraser, C.S., 1997. Digital camera self-calibration. ISPRS Journal of Photogrammetry and Remote Sensing, 52(4): 149-159.

Ghilani, C.d. ve Wolf, P.R., 2006. Adjustment Computations. 4th basim, John Wiley \& Sons, Inc.

Grange, R., Milliard, B., Vivès, S., Safa, F., Réfrégier, A., Boulade, O. ve Bertin, E., 2006. Zero distortion three mirror telescope designed for the Dark Universe Explorer (DUNE) space mission. SPIE Astronomical Telescopes + Instrumentation, 6265 (syf: 6.

Habib, A., Lin, H.T. ve Morgan, M., 2003. Autonomous Space Resection Using Point- and Line-Based Representation of Free-Form Control Linear Features. The Photogrammetric Record, 18(103): 244-258.

Jacobsen, K., 2003. Geometric Potential of IKONOS and QuickBird Images. Photogrammetric Week, Stuttgart, syf: 10 .

Kapnias, D., Milenov, P. ve Kay, S., 2008. Guidelines for Best Practice and Quality Checking of Ortho Imagery. European Commission, Joint Research Centre, Institute for the Protection and Security of the Citizen. 
Konecny, G., 1979. Methods and possibilities for digital differential rectification. Photogrammetric Engineering and Remote Sensing, 45(6): 727-734.

Kraus, K., 1993. Photogrammetry, Fundamentals and Standard Processes. Dümmler, Bonn. 397 sayfa. KURT, O., 2002. İki Boyutlu Benzerlik ve Afin Dönüşümü. Zonguldak Karaelmas Üniversitesi Mühendislik Fakültesi Joedezi ve Fotogrametri Mühendisliği Bölümü, Zonguldak.

Leprince, S., Barbot, S., Ayoub, F. ve Avouac, J.P., 2007. Automatic and precise orthorectification, coregistration, and subpixel correlation of satellite images, application to ground deformation measurements. IEEE Transactions on Geoscience and Remote Sensing, 45(6): 1529-1558.

Li, C. ve Shi, W., 2014. The Generalized-Line-Based Iterative Transformation Model for Imagery Registration and Rectification. IEEE Geoscience and Remote Sensing Letters, 11(8): 1394-1398.

Moghaddam, S.H.A., Mokhtarzade, M., Naeini, A.A. ve Amiri-Simkooei, A., 2018. A Statistical Variable Selection Solution for RFM Ill-Posedness and Overparameterization Problems. IEEE Transactions on Geoscience and Remote Sensing: 1-12.

Naeini, A.A., Moghaddam, S.H.A., Mirzadeh, S.M.J., Homayouni, S. ve Fatemi, S.B., 2017. Multiobjective Genetic Optimization of Terrain-Independent RFMs for VHSR Satellite Images. IEEE Geoscience and Remote Sensing Letters, PP(99): 1-5.

Niu, X., Hassan, T., Ellum, C. ve El-Sheimy, N., 2006. Directly georeferencing terrestrial imagery using MEMSbased INS/GNSS integrated systems. Proceedings of XXIII FIG Congress.

OGC, 1999. The OpenGIS® Abstract Specification Topic 6: The Coverage Type and its Subtypes Version 4.

Okamoto, A., 1992. Ultra-Precise Measurement Using Affine Transformation. International Archieves of Photogrammetry, Remote Sensing and Spatial Information Sciencies, Washington, D. C., XXXIX-Part B5 (syf: $318-$ 322.

Ottavianelli, G. ve Vescovi, F.D., 2018. Harmonisation of optical product types in relation to geometric corrections. Remote Sensing Letters, 9(3): 258-264.

Örmeci, C., 1988. Ortofoto'ların Sayısal Olarak Elde Edilmesi Üzerine Bir Çalışma. İstanbul Teknik Üniversitesi Dergisi, 46(3): 1-12.

Poli, D., 2005. Modelling of spaceborne linear array sensors. ETH Zürich.

RIAZANOFF, S., 2004. SPOT 123-4-5 Geometry Handbook. in: Image, S. (Ed.).

Sertel, E., Kutoglu, S.H. ve Kaya, S., 2007. Geometric correction accuracy of different satellite sensor images: application of figure condition. International Journal of Remote Sensing, 28(20): 4685-4692.

Tao, C.V. ve Hu, Y., 2001. A comprehensive study of the rational function model for photogrammetric processing. Photogrammetric Engineering and Remote Sensing, 67(12): 1347-1358.

Topan, H., 2013. First Experience with Figure Condition Analysis Aided Bias Compensated Rational Function Model for Georeferencing of High Resolution Satellite Images. Journal of the Indian Society of Remote Sensing, 41(4): 807818.

Topan, H., 2014. Dönüşüm Katsayılarının ve Sayısal Yükseklik Modelinin Konum Doğruluğunun Ortogörüntülerin Konum Doğruluğu Üzerindeki Etkisinin Belirlenmesi: Ikonos, QuickBird, OrbView-3 ve Pléiades-1A Görüntüleri ile Örnek Uygulama. 5. Uzaktan Algılama ve Coğrafi Bilgi Sistemleri Sempozyumu, İstanbul.

Topan, H., Cam, A., Oruç, M. ve Teke, M., 2016. GÖKTÜRK-2 Görüntülerinin Geometrik ve Radyometrik Açıdan Değerlendirilmesi. VI. Uzaktan Algılama ve Coğrafi Bilgi Sistemleri Sempozyumu, Adana, syf: 804-809.

Topan, H. ve Kutoglu, H.S., 2009. Georeferencing Accuracy Assessment of High-Resolution Satellite Images Using Figure Condition Method. IEEE Transactions on Geoscience and Remote Sensing, 47(4): 1256-1261.

Topan, H. ve Maktav, D., 2014. Efficiency of Orientation Parameters on Georeferencing Accuracy of SPOT-5 HRG Level-1A Stereoimages. IEEE Transactions on Geoscience and Remote Sensing, 52(6): 3683-3694. 
Topan, H., Oruç, M. ve Koçak, M.G., 2007. Ortogörüntü Üretiminde Yer Kontrol Noktası Seçimi ve Sonuçlara Etkisi. 11. Türkiye Harita Bilimsel ve Teknik Kurultayl, Ankara, syf.

Topan, H., Oruç, M., Taşkanat, T. ve Cam, A., 2014. Combined Efficiency of RPC and DEM Accuracy on Georeferencing Accuracy of Orthoimage: Case Study With Pléiades Panchromatic Mono Image. IEEE Geoscience and Remote Sensing Letters, 11(6): 1148-1152.

Topan, H., Taşkanat, T. ve Cam, A., 2013. Georeferencing Accuracy Assessment of Pléiades 1A Images Using Rational Function Model. International Archives of the Photogrammetry, Remote Sensing and Spatial Information Sciences, XL-7/W2, syf: 251-256.

Turgut, B. ve İnal, C., 2003. Nokta Konum Duyarlıklarının İki ve Üç Boyutlu Koordinat Dönüşümüne Etkisi. Coğrafi Bilgi Sistemleri ve Jeodezik A ğlar Çalıştayı, Konya, Türkiye, syf: 155-161.

Valadan Zoej, M.J., Mokhtarzade, M., Mansourian, A., Ebadi, H. ve Sadeghian, S., 2007. Rational function optimization using genetic algorithms. International Journal of Applied Earth Observation and Geoinformation, 9(4): 403-413.

Weser, T., Rottensteiner, F., Willneff, J., Poon, J. ve Fraser, C.S., 2008. Development and Testing of a Generic Sensor Model for Pushbroom Satellite Imagery. The Photogrammetric Record, 23(123): 255-274.

Yamakawa, T., 2004. Linear Orientation Models for High-Resolution Satellite Line Scanner Imagery. The University of Melbourne, Melbourne. 191 sayfa.

Yastıklı, N., 2004. Algılama Sistemlerinin Doğrudan Yöneltilmesi. Harita ve Kadastro Mühendisleri Odası Jeodezi, Jeoinformasyon ve Arazi Yönetimi Dergisi, 2004/90: 5-11.

Yaşayan, A., 1978. Hava Fotogrametrisinde İki Boyutlu Doğrusal Dönüsümler ve Uygulamalar. Karadeniz Teknik Üniversitesi, Yer Bilimleri Fakültesi. 106 sayfa.

Yavari, S., Valadan Zoej, M.J., Sahebi, M.R. ve Mokhtarzade, M., 2018. Accuracy improvement of high resolution satellite image georeferencing using an optimized line-based rational function model. International Journal of Remote Sensing, 39(6): 1655-1670.

Zhou, G., 2009. Near Real-Time Orthorectification and Mosaic of Small UAV Video Flow for Time-Critical Event Response. IEEE Transactions on Geoscience and Remote Sensing, 47(3): 739-747.

Zoej, M.J.V., 1997. Photogrammetric Evaluation of Space Linear Array Imagery For Medium Scale Topographic Mapping. Glasgow University. 303 sayfa. 